Pacific Journal of Mathematics

A NOTE ON LOOPS 


\section{A NOTE ON LOOPS}

\section{A. K. Austin}

An Associative Element of a quasigroup is defined to be an element $a$ with the property that $x(y z)=a$ implies $(x y) z=a$.

It is then shown that

(i) a quasigroup which contains an associative element is a loop,

(ii) if a loop contains an associative element then the nuclei coincide,

(iii) if a loop is weak inverse then the set of associative elements coincides with the nucleus,

(iv) if a loop is not weak inverse then no associative element is a member of the nucleus and the product of any two associative elements is not associative.

In [2] Osborn defines a Weak Inverse Loop to be a loop with the property that $x(y z)=1$ implies $(x y) z=1$. More generally we will define an Associative Element of a quasigroup to be an element $a$ with the property that $x(y z)=a$ implies $(x y) z=a$. In this note some of the properties of associative elements will be considered.

LEMMA 1. If $a$ is an associative element of a quasigroup $G$ then $(x y) z=a$ implies $x(y z)=a$.

Proof. Assume that $(x y) z=a$. Since $G$ is a quasigroup there exists an element $v$ such that $v(y z)=a$. Hence, since $a$ is associative $(v y) z=a$. Thus $(v y) z=(x y) z$ and so $x=v$ since $G$ is a quasi-group.

THEOREM 2. A quasigroup which contains an associative element is a loop.

Proof. Let $a$ be an associative element and $y$ any element of the quasigroup, then there exist elements $z$ and $b$ such that $(a y) z=a$ and $b a=a$. Thus $a=b[(a y) z]=[b(a y)] z$, since $a$ is associative. But $a=$ $(a y) z$ and so $b(a y)=a y$. However $y$ is any element of the quasigroup and so $b x=x$ for all $x$ in the quasigroup. Thus $b$ is a left unit and similarly there exists a right unit and hence a unit element.

Not all loops contain associative elements, for example the loop given by the following multiplication table. 


\begin{tabular}{l|lllll} 
& 1 & 2 & 3 & 4 & 5 \\
\hline 1 & 1 & 2 & 3 & 4 & 5 \\
2 & 2 & 5 & 4 & 1 & 3 \\
3 & 3 & 1 & 2 & 5 & 4 \\
4 & 4 & 3 & 5 & 2 & 1 \\
5 & 5 & 4 & 1 & 3 & 2
\end{tabular}

The loop given by the following multiplication table contains an associative element 2, but the unit element 1 is not associative, i.e., the loop is not weak inverse.

\begin{tabular}{l|lllll} 
& 1 & 2 & 3 & 4 & 5 \\
\hline 1 & 1 & 2 & 3 & 4 & 5 \\
2 & 2 & 1 & 4 & 5 & 3 \\
3 & 3 & 5 & 2 & 1 & 4 \\
4 & 4 & 3 & 5 & 2 & 1 \\
5 & 5 & 4 & 1 & 3 & 2
\end{tabular}

Bruck [1] defines the Left Nucleus, $N_{L}$ of a loop to be the set of those elements $n$ satisfying $(n x) y=n(x y)$ for all $x$ and $y$. The Middle and Right Nuclei, $N_{M}$ and $N_{R}$, are similarly defined. The Nucleus, $N=N_{L} \cap N_{M} \cap N_{R}$. Bruck shows that $N$ is a group. Osborn shows that the nuclei of a weak inverse loop coincide. More generally we have the following result.

THEOREM 3. If a loop contains an associative element then the nuclei coincide.

Proof. In a loop $N_{M} \neq \varnothing$ since $1 \in N_{M}$.

Let $n$ belong to $N_{M}, x$ and $y$ be any elements of the loop and $a$ be an associative element of the loop.

There exists an element $z$ such that

$$
\begin{aligned}
a & =[x(y n)] z \\
& =x[(y n) z], a \text { is associative, } \\
& =x[y(n z)], n \in N_{M}, \\
& =(x y)(n z), a \text { is associative, } \\
& =[(x y) n] z, a \text { is associative. }
\end{aligned}
$$

Thus $[x(y n)] z=[(x y) n] z$ and so $x(y n)=(x y) n$. Hence $n \in N_{R}$, and 
so $N_{M} \subseteq N_{R}$. Reversing the argument shows that $N_{R} \subseteq N_{M}$ and hence $N_{R}=N_{M}$. Similarly $N_{L}=N_{M}$.

Writing $A$ for the set of associative elements we have the following relationship between $A$ and $N$.

THEOREM 4. If a loop is weak inverse then the set of associative elements coincides with the nucleus. If a loop is not weak inverse then no associative element is a member of the nucleus and the product of any two associative elements is not associative.

Proof. We show first that if, in a loop, $A \neq \varnothing$, then $a \in A$ and $n \in N$ implies $A n=A$ and $a N=A$.

Let $n m=1$. Then since $N$ is a group $m \in M$ and $m n=1$. Also $(a n) m=a(n m)=a$.

Let $a n=(x y) z$. Then

$$
\begin{aligned}
a & =[(x y) z] m, \\
& =(x y)(z m), a \in A \\
& =x[y(z m)], \quad a \in A \\
& =x[(y z) m], \quad m \in N \\
& =[x(y z)] m, \quad a \in A .
\end{aligned}
$$

Thus $[(x y) z] m=[x(y z)] m$ and so $(x y) z=x(y z)$ and hence $a n$ is associative, i.e., $a n \in A$. Thus $A n \subseteq A$ and $a N \subseteq A$.

It follows that $A m \subseteq A$ and so $(A m) n \subseteq A n$. But $(A m) n=$ $A(m n)=A$ and so $A \subseteq A n$. Thus $A n=A$.

To show that $a N \supseteqq A$ let $b \in A$ and $a k=b$. Given elements $y$ and $z$ there exists an element $x$ such that $b=x[(y z) k]=[x(y z)] k$ since $b \in A$ and as $b=a k$ we have $a=x(y z)$ and so $a=(x y) z$.

$$
\text { Thus } \begin{aligned}
b & =[(x y) z] k \\
& =(x y)(z k) \\
& =x[y(z k)] \text { since } b \in A .
\end{aligned}
$$

Hence $x[(y z) k]=x[y(z k)]$ and so $(y z) k=y(z k)$. Thus $k \in N$ and so $b \in a N$ and $A \subseteq a N$. Hence $A=a N$. In a weak inverse loop $1 \in A$ and so $N=1 N=A$.

If $A \cap N \neq \varnothing$, say $y \in A \cap N$ then $y N=A$ and $y N=N$ since $N$ is a group and so $A=N$. But $1 \in N$ and hence $1 \in A$, i.e., the loop is weak inverse.

If $A A \cap A \neq \varnothing$, then there exist $a, b, c \in A$ such that $a b=c$. But $a N=A$ and so $a n=c$ for some $n \in N$. Thus $b=n$, i.e., $b \in N$ and so $A \cap N \neq \varnothing$ and hence the loop is weak inverse. This completes the proof of Theorem 4 . 


\section{REFERENCES}

1. R. H. Bruck, Pseudo-automorphisms and Moufang loops, Proc. Amer. Math. Soc. 3 (1952), 66-72.

2. J. M. Osborn, Loops with the weak inverse property, Pacific J. Math. 10 (1960), 295-304.

Received June 10, 1965. 


\section{PACIFIC JOURNAL OF MATHEMATICS}

\section{EDITORS}

H. SAMELSON

Stanford University

Stanford, California

R. M. BLUMENTHAL

University of Washington

Seattle, Washington 98105

\section{*J. DugundJI}

University of Southern California Los Angeles, California 90007

RICHARD ARENS

University of California

Los Angeles, California 90024

\section{ASSOCIATE EDITORS}

E. F. BECKENBACH
F. WOLF

K. YosIDA

\section{SUPPORTING INSTITUTIONS}

\author{
UNIVERSITY OF BRITISH COLUMBIA \\ CALIFORNIA INSTITUTE OF TECHNOLOGY \\ UNIVERSITY OF CALIFORNIA \\ MONTANA STATE UNIVERSITY \\ UNIVERSITY OF NEVADA \\ NEW MEXICO STATE UNIVERSITY \\ OREGON STATE UNIVERSITY \\ UNIVERSITY OF OREGON \\ OSAKA UNIVERSITY \\ UNIVERSITY OF SOUTHERN CALIFORNIA
}

\author{
STANFORD UNIVERSITY \\ UNIVERSITY OF TOKYO \\ UNIVERSITY OF UTAH \\ WASHINGTON STATE UNIVERSITY \\ UNIVERSITY OF WASHINGTON \\ AMERICAN MATHEMATICAL SOCIETY \\ CHEVRON RESEARCH CORPORATION \\ TRW SYSTEMS \\ NAVAL ORDNANCE TEST STATION
}

Mathematical papers intended for publication in the Pacific Journal of Mathematics should be typewritten (double spaced). The first paragraph or two must be capable of being used separately as a synopsis of the entire paper. It should not contain references to the bibliography. Manuscripts may be sent to any one of the four editors. All other communications to the editors should be addressed to the managing editor, Richard Arens at the University of California, Los Angeles, California 90024 .

50 reprints per author of each article are furnished free of charge; additional copies may be obtained at cost in multiples of 50 .

The Pacific Journal of Mathematics is published monthly. Effective with Volume 16 the price per volume (3 numbers) is $\$ 8.00$; single issues, $\$ 3.00$. Special price for current issues to individual faculty members of supporting institutions and to individual members of the American Mathematical Society: $\$ 4.00$ per volume; single issues $\$ 1.50$. Back numbers are available.

Subscriptions, orders for back numbers, and changes of address should be sent to Pacific Journal of Mathematics, 103 Highland Boulevard, Berkeley 8, California.

Printed at Kokusai Bunken Insatsusha (International Academic Printing Co., Ltd.), No. 6, 2-chome, Fujimi-cho, Chiyoda-ku, Tokyo, Japan.

PUBLISHED BY PACIFIC JOURNAL OF MATHEMATICS, A NON-PROFIT CORPORATION

The Supporting Institutions listed above contribute to the cost of publication of this Journal, but they are not owners or publishers and have no responsibility for its content or policies.

* Paul A. White, Acting Editor until J. Dugundji returns. 


\section{Pacific Journal of Mathematics}

\section{Vol. 18, No. 2 \\ April, 1966}

Alexander V. Arhangelskii, On closed mappings, bicompact spaces, and a problem of P. Aleksandrov .............................. 201

A. K. Austin, A note on loops . . . . . . . . . . . . . . . . . . . . . . . . . . . . 209

Lawrence Peter Belluce and William A. Kirk, Fixed-point theorems for families of contraction mappings...................... 213

Luther Elic Claborn, Every abelian group is a class group ............ 219

Luther Elic Claborn, A note on the class group .................. 223

Robert Stephen De Zur, Point-determining homomorphisms on multiplicative semi-groups of continuous functions............. 227

Raymond William Freese, A convexity property ................ 237

Frederick Paul Greenleaf, Characterization of group algebras in terms of their translation operators ......................... 243

Andrzej Hulanicki, On the spectral radius of hermitian elements in group algebras....................................... 277

Michael Bahir Maschler and Bezalel Peleg, A characterization, existence proof and dimension bounds for the kernel of a game ............ 289

Yiannis (John) Nicolas Moschovakis, Many-one degrees of the predicates

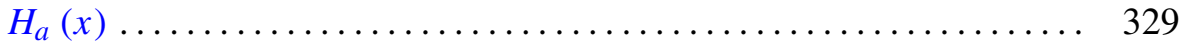

G. O. Okikiolu, $n$th order integral operators associated with Hilbert transforms.

C. E. Rickart, Analytic phenomena in general function algebras ... 361

K. N. Srivastava, On an entire function of an entire function defined by Dirichlet series

Paul Elvis Waltman, Oscillation criteria for third order nonlinear differential equations .......................... 